\title{
The Response of the Tongue Epithelial on Cigarette Smoke Exposure as a Risk Factor for Oral Cancer Development
}

\author{
Neken Prasetyaningtyas ${ }^{1}$ Nabilah Azzahra Jatiatmaja ${ }^{1}$ Desiana Radithia ${ }^{2}$ Hening Tuti Hendarti \\ Adiastuti Endah Parmadiati² Priyo Hadi² Fatma Yasmin Mahdani ${ }^{2}$ Diah Savitri Ernawati² \\ Rosnah binti Zain ${ }^{3}$ Nurina Febriyanti Ayuningtyas²
}

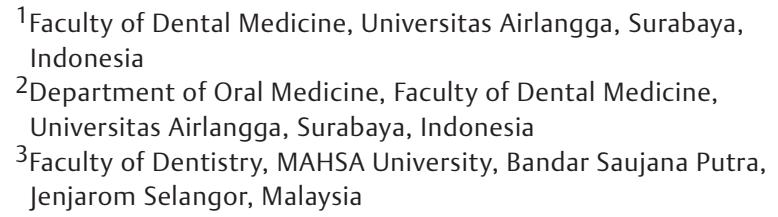

Address for correspondence Nurina Febriyanti Ayuningtyas, drg, MKes, PhD, SpPM, Department of Oral Medicine, Faculty of Dental Medicine, Universitas Airlangga, Surabaya 60132, Indonesia (e-mail: nurina-ayu@fkg.unair.ac.id).

Eur J Dent 2021;15:320-324

\begin{abstract}
Objective The aim of this study is to analyze the tongue epithelial response to cigarette smoke exposure on a number of macrophages, lymphocytes, plasma cells, and matrix metalloproteinase 9 (MMP-9) expression to determine the risk factor of oral cancer development.

Materials and Methods Thirty Rattus norvegicus will be exposed to two kinds of cigarette smoke by a smoking pump for 4 and 8 weeks. The tongues were collected to analyze the number of macrophages, lymphocytes, and plasma cells with hematoxylin-eosin. The MMP-9 expression was similarly analyzed with immunohistochemical staining and then compared with the control group.

Results The number of macrophages, lymphocytes, and MMP-9 expression was higher in the 8-week cigarette smoke exposure compared to the 4-week cigarette smoke exposure and the control group $(p<0.000)$. The number of plasma cell did not

Keywords

- cigarette smoke

- lymphocytes

- macrophages

- MMP-9 expression

- tongue differ in the 8-week cigarette smoke exposure from that of the control group $(p>0.05)$. The number of plasma cells in the tongue tissue during the 4-week cigarette smoke exposure was not determined.

Conclusion Cigarette smoke exposure induces the risk of oral cancer development as a result of an increase in the number of macrophages, lymphocytes, and MMP-9 expression in the tongue epithelial.
\end{abstract}

\section{Introduction}

Health problems caused by cigarettes do not only affect active smokers but also passive smokers. Various studies have shown that passive smoking has the same health risks as active smoking. More than two-thirds of Indonesia's population has been exposed to cigarette smoke since birth. The highest occurrence of passive smoking is in children aged 5 to

published online

December 7, 2020
DOI https://doi.org/

10.1055/s-0040-1721312 ISSN $1305-7456$.
19 years and in women of reproductive age between 15 and 49 years. ${ }^{1}$ Smoking can cause 15 types of cancer, including oral precancerous and cancerous lesion. In Indonesia, cases of oral cancer range from 3 to $4 \%$ of all cancer cases, and the mortality rate reaches 2 to $3 \%$ of the total number of deaths due to malignancy. ${ }^{2-4}$

Tobacco use has become a big problem for health around the world. Tobacco products contain thousands of chemical (c) 2020. European Journal of Dentistry.

This is an open access article published by Thieme under the terms of the Creative Commons Attribution-NonDerivative-NonCommercial-License, permitting copying and reproduction so long as the original work is given appropriate credit. Contents may not be used for commercial purposes, or adapted, remixed, transformed or built upon. (https://creativecommons.org/licenses/by-nc-nd/4.0/)

Thieme Medical and Scientific Publishers Pvt. Ltd., A-12, 2nd Floor, Sector 2, Noida-201301 UP, India 
constituents, including nicotine, noricotine, and anabasine. Nicotine reacts with nitrite to produce specific nitrosamines such as 4-(methyl nitrosamino)-1-(3-pyridyl)-1-butanone and 4-(methyl nitrosamino)-1-(3-pyridyl)-1-butanol. These products lead to the production of reactive oxygens species (ROS), which are known to activate nuclear factor kappa beta $(\mathrm{NF}-\mathrm{kB})^{5}$ and cause DNA mutations that stimulate the growth of oral cancer. ${ }^{6}$

The pathogenesis of oral cancer is not fully understood. Smoking, alcohol consumption, exposure to radiation, and chemical carcinogens are postulated as the main risk factors. Smoking will lead to an inflammatory response in the oral mucosa due to the production of heat, smoke, and the products contained within the cigarettes. These products cause inflammatory responses in the oral mucosa ${ }^{7}$ and can lead to the development of oral cancer. ${ }^{8}$ The inflammation process involves the recruitment of inflammatory cells. One inflammatory cell, which has an important role in the development of oral cancer, is macrophages as this type of cell produces pro-inflammatory cytokine. ${ }^{9}$ Cytokines are essential constituents in the microenvironment of cancers due to their ability to invade and metastasize, and can promote cell proliferation and survival. ${ }^{10}$ Other inflammatory cells such as lymphocyte cells are indicators of the onset of chronic inflammation. ${ }^{11}$

Matrix metalloproteinase 9 (MMP-9) is a protease enzyme that has the potential to be a cancer marker, including oral cancer. MMP-9 is involved in the early development and growth of cancer. ${ }^{12}$ Moreover, MMP-9 is an endopeptidase enzyme that has a role in the division and destruction of extracellular matrix substrates, and regulates various protein activities. ${ }^{13}$ It also has a high presence in the gelatinolytic process, which degrades collagen types IV, V, VII, IX, and X, fibronectin, e-cadherin, and elastin. MMP-9 is secreted by cells of the human body, such as fibroblast cells, endothelial cells, polymorphonuclear cells, keratinocytes, macrophages, and epithelial cells. ${ }^{14}$ MMP-9 expression increases during cancer growth and therefore considered capable of being a marker for cancer diagnostic and prognosis. ${ }^{15}$ However, no studies have evaluated the increase of inflammatory cell and MMP-9 expression during exposure to cigarette smoke. The purpose of this study is to determine the number of macrophages, lymphocytes, plasma cells, and MMP-9 expression on the tongue epithelial of Rattus norvegicus exposed to cigarette smoke as an indicator of the risk factor for oral cancer.

\section{Materials and Methods}

\section{Animals}

All experimental animals were treated by following the regulations on Animal Care and Use Committee of Airlangga University. The protocol was approved by the Health Research Ethical Clearance Committee, Faculty of Dental Medicine with the registration number 181/HRECC.FODM/IX/2017. This study used a sample of $30 R$. norvegicus-3-month-old male and weighing between 170 and $200 \mathrm{~g}$-that is selected based on the benchmarks of healthy mice, which includes clear-eyed features, shiny fur, agile movements, and good feces.

\section{Cigarette Smoke Exposure}

Cigarette smoke exposure was artificially created using a smoking pump. The animal placed in a room that was connected to a smoking chamber by a valve. The valve serves to equalize the dose of smoke coming into each of the mouse tubes so that the animals were actively exposed to cigarette smoke. Two cigarettes per day were burned and exposed to the animal for either 4 or 8 weeks.

\section{Tissue Collection}

After all the animals had been exposed to cigarette smoke for 4 or 8 weeks, excluding the control group who were not exposed, the animals were then sacrificed. The tongues were dissected, and a histology preparation procedure and paraffin block were conducted.

\section{Number of Macrophages, Lymphocytes, and Plasma Cell}

The tongue tissue was stained using hematoxylin-eosin to directly count the number of macrophages, lymphocytes, and plasma cell. This was done in five different field light microscopes, with $\times 1,000$ magnification using a Nikon H600L microscope with a 300-megapixel DS Fi2 camera and the Nikon Image System picture software procession.

\section{Matrix Metalloproteinase 9 Expression}

The MMP-9 expression is a collagenase type IV proteolytic enzyme in which the observed expression stains a brownish color in the cytoplasm of cells undergoing dysplasia using MMP-9 monoclonal antibodies by immunohistochemical methods. The stain was analyzed by directly counting the immunoreactive cell in the basal and suprabasal regions in 20 different field light microscopes, with $\times 1,000$ magnification using a Nikon H600L microscope with a 300-megapixel DS Fi2 camera and the Nikon Image System picture software procession.

\section{Statistical Analysis}

The results of the data obtained were statistically analyzed using the Statistical Package for the Social Sciences. Data analysis was performed by using the Kolmogorov-Smirnov test to test for normality and Levene's test for homogeneity. One-way analysis of variance would be carried out to compare the MMP-9 expression between each treatment group. The number of macrophages, lymphocytes, and plasma cells was analyzed using the Kruskal-Wallis and Mann-Whitney test to compare each treatment group. A $p$-value $<0.05$ was considered as different.

\section{Results}

\section{Number of Macrophages, Lymphocytes, and Plasma Cell}

The number of macrophages, lymphocytes, and plasma cells is presented in - Fig. 1. The macrophages cells in the tongue 
epithelial after 8 weeks of cigarette smoke exposure $(10.20$ \pm 8.69 ) was greater than 4 weeks of cigarette smoke exposure $(8.60 \pm 5.29)$ and the control $(5.80 \pm 6.29)(p=0.000)$. The macrophages cells in the tongue epithelial exposed to 4 weeks of cigarette smoke $(8.60 \pm 5.29)$ showed a higher number than that of the control group $(5.80 \pm 6.29 ; p=$ 0.014;- Table 1).

The lymphocytes cells in the tongue epithelial after 8 weeks of cigarette smoke exposure $(23.40 \pm 13.26)$ showed a higher number in comparison to 4 weeks of cigarette smoke exposure $(9.80 \pm 10.15)$ and the control group ( $0.80 \pm 2.62$; $p=0.000)$. The macrophages cells in the tongue epithelial after 4 weeks of cigarette smoke exposure $(9.80 \pm 10.15)$ was higher than the control group ( $4.80 \pm 2.62 ; p=0.009$; - Table 1).The plasma cell in the tongue epithelial showed no difference in either 8 or 4 weeks of cigarette smoke exposure when compared to the control group $(p=0.135$; - Table 1).

\section{Matrix Metalloproteinase 9 Expression}

The MMP-9 expression was calculated from the cytoplasm of the basal and parabasal epithelial cells, which showed brown
MMP-9 expression ( - Fig. 2). The MMP-9 expression in the tongue epithelial after 8 weeks of cigarette smoke exposure $(13.10 \pm 2.38)$ showed a higher number than both the 4 weeks of cigarette smoke exposure $(8.80 \pm 3.46)$ and the control group ( $5.00 \pm 1.89 ; p=0.010$ and $p=0.000$, respectively). The MMP-9 expression in the tongue epithelial after 4 weeks of cigarette smoke exposure $(8.80 \pm 3.46)$ showed a higher number than the control group $(5.00 \pm 1.89 ; p=0.000$;

\section{- Table 1).}

\section{Discussion}

Continuous exposure to cigarette smoke can cause persistent lesions on the oral mucosa. With such injuries, the body will respond with self-defense, which causes a chronic inflammatory process as a response to long-term cigarette smoke exposure. The occurring inflammation is indicated by the presence of activated inflammatory cells. The chronic inflammation is characterized by the infiltration of mononuclear cells such as macrophages, lymphocytes, and plasma cells in the tissue, resulting in tissue destruction. These cells cause the increase
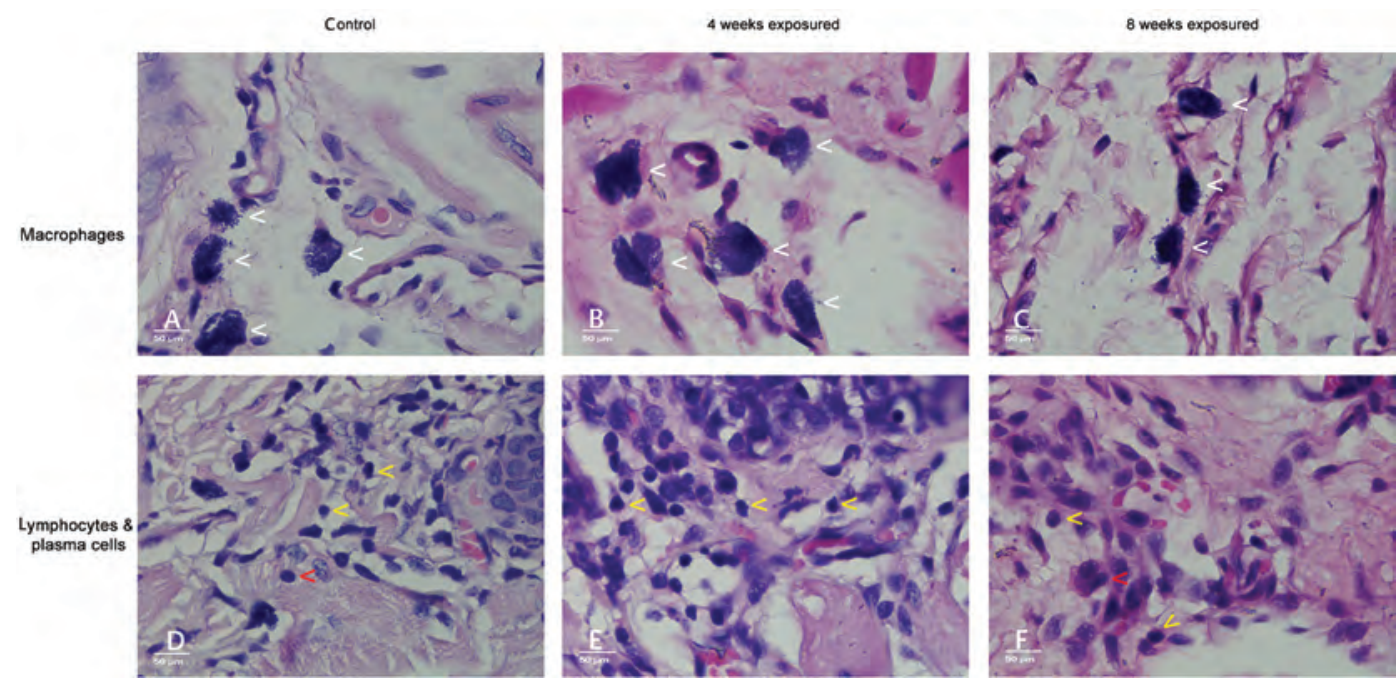

Fig. 1 The macrophages cells (white arrow), lymphocytes (yellow arrow), and plasma cells (red arrow) in the tongue epithelial ( $\times 1,000$ magnification). Control group (A, D), 4-week cigarette smoke exposure (B, E), and 8-week cigarette smoke exposure (C, F).

Table 1 The mean of Matrix metallopeptidase 9 expression, number of lymphocytes, macrophages, and plasma cell in the tongue epithelial

\begin{tabular}{|l|l|l|l|l|}
\hline Marker & Control & 4-week exposure & 8-week exposure & $p$-Value \\
\hline MMP-9 & $5.00 \pm 1.89^{\mathrm{a}, \mathrm{b}}$ & $8.80 \pm 3.46^{\mathrm{a}, \mathrm{c}}$ & $13.10 \pm 2.38^{\mathrm{b}, \mathrm{c}}$ & $\begin{array}{l}0.000^{\mathrm{a}, \mathrm{b}} \\
0.010^{\mathrm{c}}\end{array}$ \\
\hline Macrophages & $5.80 \pm 6.29^{\mathrm{d}, \mathrm{e}}$ & $8.60 \pm 5.29^{\mathrm{d}, \mathrm{f}}$ & $10.20 \pm 8.69^{\mathrm{e}, \mathrm{f}}$ & $0.014^{\mathrm{d}}$ \\
& & & & $0.000^{\mathrm{e}, \mathrm{f}}$ \\
\hline Lymphocytes & $4.80 \pm 2.62^{\mathrm{d}, \mathrm{e}}$ & $9.80 \pm 10.15^{\mathrm{d}, \mathrm{f}}$ & $23.40 \pm 13.26^{\mathrm{e}, \mathrm{f}}$ & $0.009^{\mathrm{d}}$ \\
& & & & $0.000^{\mathrm{e}, \mathrm{f}}$ \\
\hline Plasma cells & $0.2 \pm 0.63$ & 0 & $0.7 \pm 1.16$ & $0.135^{\mathrm{g}}$ \\
\hline
\end{tabular}

Abbreviations: MMP-9, matrix metallopeptidase 9; LST, least significant difference.

Note: the data presented as mean \pm standard deviation. The same character in the marker column shows significant differences in each group.

${ }^{a-c}$ Significant differences with LSD test, with $p<0.05$.

d-fSignificant differences with the Mann-Whitney test, with $p<0.05$.

gSignificant value with Kruskal-Wallis test $p<0.05$. 


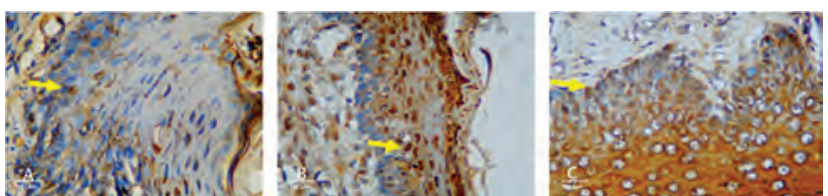

Fig. 2 Matrix metallopeptidase 9 expression around cells and in cytoplasm (yellow arrow; $\times 1,000$ magnification). Control group (A), 4-week cigarette smoke exposure (B), and 8-week cigarette smoke exposure $(\mathbf{C})$.

of ROS. ${ }^{16}$ The increase in ROS will cause oxidative stress, which can induce DNA damage and genomic instability.

Lymphocyte cells are seen indicating the onset of chronic inflammation. This inflammation causes widespread cell and tissue damage, causing increased macrophage cell activation. The presence of increased macrophage cells will activate lymphocytes, which are markers of a chronic inflammatory phase. Phagocytosis by these macrophages causes the macrophages to present an antigen that is recognized by T-CD4 lymphocytes. The activation of T-CD4 ${ }^{+}$ cells causes an even greater immune response. T-CD4 $4^{+}$cells have great potential to produce interleukin 2 (IL-2), which is an interleukin that is very influential in increasing cell proliferation. The IL-2 is not only utilized by T-CD4 ${ }^{+}$cells but also by $\mathrm{T}-\mathrm{CD} 8^{+}$and $\mathrm{B}$ cells, which differentiate into plasma cells. ${ }^{11}$ Additionally, this research confirmed the increase of lymphocytes and macrophages after exposure to cigarette smoke for 8 weeks. Another study conducted by Zaquia et al supports the results of this study-noting an increase in the inflammatory cell when studying the effect of passive smoking on the larynx and trachea over a period of 120 days-used cigarettes containing $10 \mathrm{mg}$ tar and $0.8 \mathrm{mg}$ nicotine and one cigarette per day for each animal. ${ }^{17}$ While this study used cigarettes contained $34 \mathrm{mg}$ tar and $2.1 \mathrm{mg}$ nicotine, the highest content of tar and nicotine not only caused the chronic inflammatory response with the presence of lymphocytes and macrophages but also saw the occurrence of hyperplasia and dysplasia. A previous study by Ayuningtyas et al, which examined cigarette smoke exposure over the course of 4 and 8 weeks with the same cigarette, saw that there were no clinical changes of the oral mucosal specifically on the tongue and oropharyngeal mucosal, but there were histological changes of hyperplasia and dysplasia. At 4 weeks, mild dysplasia developed, and at 8 weeks it changed to moderate and severe dysplasia. ${ }^{18,19}$ The results of the study proved that long-term cigarette smoke exposure and cigarette composition contributed to the risk factor of oral cancer development, along with the presence of hyperplasia and dysplasia as a marker of histological changes; thus, in this study we would like to elucidate cellular and molecular changes due to long-term cigarette smoke exposure through examining level of chronic inflammatory cells infiltration as a marker of chronic inflammation and MMP-9 as a marker for invasion and metastasis. ${ }^{20}$

No changes can be seen on plasma cell level in this study between control and treatment group was in line to several previous studies might due to downregulation of B cell. Studies on humans generated contradictory data showing that cigarette smoking increases frequency of memory $B$ cells and IgE production, lowers regulatory B cell numbers, but decreases production of IgA, IgG, and IgM in smokers while smoke exposure downregulates murine marrow pre-B cells or pro-B cells. ${ }^{21}$ Another study showed a number of B cells were not affected by smoking. ${ }^{22}$ In summary, smoking might alter immune response by affecting B cell.

The results of this study showed an increase in MMP-9 expression proportional to the increased inflammatory cells, which was later confirmed by Ayuningtyas et al, who noted an increase in severity of the degree of dysplasia. The mechanism proves that continuous smoke exposure will cause a chronic inflammatory response accompanied by tissue destruction. Chronic inflammation means a persistent inflammation that causes increased chronic inflammatory cells such as macrophages, lymphocytes, and plasma cells due to increased ROS as a result of exposure to smoke. These chronic inflammatory cells then release the metalloproteinase-9 matrix, which facilitates the occurrence of malignancy. ${ }^{23}$ Matrix metalloproteinase is a group of enzymes that can damage the bonds between cells and extracellular matrix. It is thought to play a role in the process of carcinogenesis of epithelial cells, including the oral epithelium. Among many matrixine families, MMP-9 is matrixine type that has the highest collagen degradation activity. Therefore, MMP-9 is more widely observed and considered as a biomarker for the diagnosis and prognosis of cancer. MMP-9 is secreted by fibroblast cells, endothelial cells, and inflammatory cells such as polymorphonuclear neutrophils, keratinocytes, and macrophages. Moreover, MMP-9 plays a role in carcinogenesis in two stages. The first stage is actively involved in the occurrence of dysplasia and is followed by the next stage in the development of dysplasia toward carcinoma. ${ }^{23}$ In the early stages, MMP-9 plays a role in cell proliferation by activating several growth factors, such as a transformative growth factor $\alpha$ (TGF- $\alpha$ ) which might induce hyperplasia, as well as damaging the attachment between cells to form microenvironment, which supports changes in cell morphology lead to metastasis. The inflammatory mediators, including NF-kB, vascular endothelial growth factor, inflammatory cytokines, prostaglandin pathways, p53 activation, ${ }^{24,25}$ reactive oxygen and nitrogen species, and microRNAs, are major players in the pathogenesis of oral cancer. ${ }^{5}$ Activation of ROS has a pathological effect besides causing DNA mutations, such irritating the mucous membrane, which causes an inflammatory reaction. Moreover, ROS also degrades inhibitory kappa B (IkB), which causes an increase in NF-kB in the nucleus. This attracts more inflammatory cells such as neutrophils and macrophages. These inflammatory cells produce MMP-9 collagenase enzymes that have destructive abilities, E-cadherin, which is the adhesive between cells. MMP-9 also damages collagen type 4, damaging fibronectin and elastin, which facilitates dysplasia. ${ }^{26}$ Similarly, ROS also causes a decrease in the tissue inhibitor of metalloproteinase (TIMP-1) expression by transforming the growth factor $\beta 1$ (TGF- $\beta 1$ ), which is an antiproliferative agent. TIMP- 1 is a 
natural inhibitor of MMP-9; thus, the inhibition of TIMP-1 production causes the excessive expression of MMP-9. ${ }^{15}$

The results also show the presence of MMP-9 expression in normal epithelial tissue. The MMP-9 expression was present in the cytoplasm and cell-extracellular tissue due to the activity of fibroblasts which can induce MMP-9 expression in physiological processes. ${ }^{27,28}$ The MMP-9 expression in the noncigarette smoke exposed group was lower than the groups of 4 and 8 weeks cigarette smoke exposure. The increase of MMP-9 expression was followed by an increase in the inflammatory cells.

\section{Conclusion}

Cigarette smoke exposure induces the risk of oral cancer development due to the increased number of macrophages, lymphocytes and MMP-9 expressions in the tongue epithelial.

\section{Funding}

This study is funded by the Faculty of Dental Medicine Universitas Airlangga 2019 in the Schema Penelitian Unggulan Fakultas.

\section{Conflict of Interest}

None declared.

\section{References}

1 Idris S, Baqays A, Isaac A, Chau JKM, Calhoun KH, Seikaly H. The effect of second hand smoke in patients with squamous cell carcinoma of the head and neck. J Otolaryngol Head Neck Surg 2019;48(1):33

2 Sierra H, Cordova M, Chen CJ, Rajadhyaksha M. Confocal imaging-guided laser ablation of basal cell carcinomas: an ex vivo study. J Invest Dermatol 2015;135(2):612-615

3 Ghallab NA, Shaker OG. Serum and salivary levels of chemerin and MMP-9 in oral squamous cell carcinoma and oral premalignant lesions. Clin Oral Investig 2017;21(3):937-947

4 Sood P, Narang R, Swathi V, Mittal L, Jha K, Gupta A. Dental patient's knowledge and perceptions about the effects of smoking and role of dentists in smoking cessation activities. Eur J Dent 2014;8(2):216-223

5 Patel JB, Shah FD, Joshi GM, Patel PS. Clinical significance of inflammatory mediators in the pathogenesis of oral cancer. J Cancer Res Ther 2016;12(2):447-457

6 Valavanidis A, Vlachogianni T, Fiotakis K. Tobacco smoke: involvement of reactive oxygen species and stable free radicals in mechanisms of oxidative damage, carcinogenesis and synergistic effects with other respirable particles. Int J Environ Res Public Health 2009;6(2):445-462

7 Sundar IK, Javed F, Romanos GE, Rahman I. E-cigarettes and flavorings induce inflammatory and pro-senescence responses in oral epithelial cells and periodontal fibroblasts. Oncotarget 2016;7(47):77196-77204

8 Tampa M, Mitran MI, Mitran CI, et al. Mediators of inflammation: a potential source of biomarkers in oral squamous cell carcinoma. J Immunol Res 2018;2018:1061780

$9 \mathrm{Ng} \mathrm{WK}$, Wong SH, Ng SC. Changing epidemiological trends of inflammatory bowel disease in Asia. Intest Res 2016;14(2):111-119

10 Goertzen C, Mahdi H, Laliberte C, et al. Oral inflammation promotes oral squamous cell carcinoma invasion. Oncotarget 2018;9(49):29047-29063
11 Bhat TA, Kalathil SG, Bogner PN, et al. Secondhand smoke induces inflammation and impairs immunity to respiratory infections. J Immunol 2018;200(8):2927-2940

12 Gracia I, Utoro T, Supriatno S, Astuti I, Heriyanto DS, Pramono D. Epidemiologic profile of oral squamous cell carcinoma in Yogyakarta, Indonesia. Padjadjaran J Dent 2017; 29(1):32-37

13 Venugopal A, Uma Maheswari TN. Expression of matrix metalloproteinase-9 in oral potentially malignant disorders: a systematic review.J Oral Maxillofac Pathol 2016;20(3):474-479

14 Peschos D, Damala C, Stefanou D, et al. Expression of matrix metalloproteinase-9 (gelatinase B) in benign, premalignant and malignant laryngeal lesions. Histol Histopathol 2006;21(6):603-608

15 Chandolia B, Basu SK, Kumar M. Can MMP-9 be a prognosticator marker for oral squamous cell carcinoma? J Clin Diagn Res 2016;10(1):ZC09-ZC13

16 Lee J, Taneja V, Vassallo R. Cigarette smoking and inflammation: cellular and molecular mechanisms. J Dent Res 2012; 91(2):142-149

17 Zaquia Leão $\mathrm{H}$, Galleano Zettler C, Cambruzzi E, et al. The effects of passive smoking on laryngeal and tracheal mucosa in male wistar rats during growth: an experimental study. J Voice 2017;31(1):126.e19-126.e24

18 Ayuningtyas NF, Mahardika GO, Soebadi B, et al. Hyperplasia of Wistar rat tongue mucosa due to exposure to cigarette side-stream smoke. Dent J 2019;52(3):133

19 Ayuningtyas NF, Endah A, Permatasari A, et al. The increase of dysplasia level in Wistar rats oropharyngeal mucosa exposed by sidestream cigarette smoke. Eurasia J Biosc 2020;14:3641-3646

20 de Oliveira Semenzati G, de Souza Salgado B, Rocha NS, Michelin Matheus SM, de Carvalho LR, Garcia Martins RH. Histological and immunohistochemical study of the expression of p53 and ki-67 proteins in the mucosa of the tongue, pharynx and larynx of rats exposed to cigarette smoke. Inhal Toxicol 2012;24(11):723-731

21 Qiu F, Liang C-L, Liu H, et al. Impacts of cigarette smoking on immune responsiveness: up and down or upside down? Oncotarget 2017;8(1):268-284

22 Loos BG, Roos MTL, Schellekens PTA. van der Velden U, Miedema F. Lymphocyte numbers and function in relation to periodontitis and smoking. J Periodontol 2004;75(4):557-564

23 Hauff SJ, Raju SC, Orosco RK, et al. Matrix-metalloproteinases in head and neck carcinoma-cancer genome atlas analysis and fluorescence imaging in mice. Otolaryngol Head Neck Surg [Internet] 2014;151(4):612-618

24 Irmawati A, Handayani ATW, Balqis NF, Surboyo MDC. The decreased of p53 mutant expression on squamous cell epithelial of oral in mus musculus by moderate intensity of exercise. Malaysian J Med Heal Sci 2020;16(July):1-5

25 Arundina I, Budhy TI, Surboyo MDC. Meloxicam inhibit the growth of oral squamous cell carcinoma induced by benzopyrenes. Malaysian J Med Heal Sci 2020;16(4):22-25

26 Fan HX, Li HX, Chen D, Gao ZX, Zheng JH. Changes in the expression of MMP2, MMP9, and ColIV in stromal cells in oral squamous tongue cell carcinoma: relationships and prognostic implications. J Exp Clin Cancer Res 2012;31(1):90

27 Tsai CH, Hsieh YS, Yang SF, Chou MY, Chang YC. Matrix metalloproteinase 2 and matrix metalloproteinase 9 expression in human oral squamous cell carcinoma and the effect of protein kinase $C$ inhibitors: preliminary observations. Oral Surg Oral Med Oral Pathol Oral Radiol Endod [Internet] 2003;95(6):710-716

28 Murnane MJ, Cai J, Shuja S, McAneny D, Willett JB. Active matrix metalloproteinase-2 activity discriminates colonic mucosa, adenomas with and without high-grade dysplasia, and cancers. Hum Pathol 2011;42(5):688-701 